EPiC Series in Computing
Volume 78, 2021, Pages 77-88
Proceedings of the European Univer-
sity Information Systems Conference 2021

\title{
Progress on Digitization of Higher Education Processes towards Standards EU \& DE
}

\author{
H. Strack ${ }^{1,2}$, G. Bacharach ${ }^{3}$, R.-D. Steiper ${ }^{4}$, M. Gottlieb ${ }^{5}$, W. Radenbach ${ }^{4}$, A. \\ Waßmann ${ }^{6}$, H. Pongratz $z^{5}$ and J.J. Norder ${ }^{7}$ \\ ${ }^{1}$ Hochschule Harz, Germany; ${ }^{2}$ CyberSec-LSA, Germany \\ ${ }^{3}$ Stiftung für Hochschulzulassung (SfH), Germany \\ ${ }^{4}$ Georg-August Universität Göttingen, Germany \\ ${ }^{5}$ Technische Universität München (TUM), Germany \\ ${ }^{6}$ Hochschul-Informations-System eG (HIS), Germany \\ ${ }^{7}$ Dienst Uitvoering Onderwijs, The Netherlands \\ hstrack@hs-harz.de, guido.bacharach@hochschulstart.de, \\ \{ramona-denisa.steiper|wolfgang.radenbach\}@uni-goettingen.de, \\ \{matthias.gottlieb|pongratz\}@tum.de, \\ wassmann@his.de, janjoost.norder@duo.nl
}

\begin{abstract}
We present ongoing developments and projects concerning the digitization of Higher Education Use Cases, Processes and Infrastructures in the context of EU developments and standardization efforts (EU SDG). These use cases and projects include: (i) student applications at Higher Education Institution (HEI) portals at HEI and at the Stiftung für Hochschulzulassung $(\mathrm{SfH})$ sites for admissions; (ii) secure and trustworthy production of exam certificates for HEI and EDU applications; (iii) student mobility digitization, e. g. ELMO, EMREX, EDCI, eIDAS, PIM, and (iv) standardization efforts embedded in the EU contexts such as XHigherEducationInstitutionExchange (XHEIE).

Orchestrating the process participants ( $\mathrm{SfH}$, universities, applicants) is necessary for effective operation and calls for the strategic and systematic expansion of digitization. In the future the Online Access Act (OZG) reinforces the need to digitize admissions processes operated by the participants.
\end{abstract}

\section{Introduction}

The German Online Access Act (OZG) reinforced the need for the digitisation of HEI processes. This obliges the German federal state, local states and (municipality) public authorities to offer their 
administrative services digitally via administrative portals and web applications by the end of 2022, e.g. as main processes at HEI/EDU level for university admission and for generation of graduation certificates and diplomas at Schools or HEI. The OZG user/citizen accounts (OZG UAC) allow authentication of the user on different levels of assurance (LoA eIDAS), to log on securely and to transfer application data to the web applications / portals of public authorities, especially on eIDAS authentication LoA level "high", by using the German identity card (eID/geID). In the future, this will be also enabled in an eIDAS interoperable way for OZG users from other EU Member States (EU MS), with EU notified ID LoA Level "high". Application Decisions of the public authority could be transferred back to the OZG UAC (digital application and decision with legally binding).

Additionally, a kind of "Single Sign On" (SSO) is offered to the users and to the public authorities website providers (OZG UAC mostly offered by the 16 local states and the federal state). Already before the completion of the OZG UAC implementations (2022), the public authorities were allowed to implement directly an eID/geID based logon on their own website, like at Hochschule Harz since 2012/2013 (eID UAC).

\section{Use Cases for HEI/EDU - Admissions (UC1)}

We distinguish in the federal Germany two kinds of University Admission processes: a centralized and a decentralized type.

\subsection{Centralized Admissions}

Under the brand name "hochschulstart", the "Foundation for University Admissions" ("Stiftung für Hochschulzulassung" - $\mathrm{SfH}$ ) operates a service or service platform for access to studies at staterecognized universities. On behalf of the federal states, the study places for the nationally restricted study courses in medicine, veterinary medicine, dentistry and pharmacy are allocated centrally via hochschulstart.de (numerus clausus NC). In addition, on behalf of the universities, the admissions offers for both locally restricted and unrestricted study courses are coordinated at well over 100 locations.

For many prospective students, the hochschulstart is the central partner on their way to university. For this reason, hochschulstart not only provides the opportunity to apply online, but also offers a wide range of information on the relevant processes and provides valuable tips on how to optimize individual admission chances. Despite these clearly digitally oriented fields of activity, however, the everyday life of the foundation shows media discontinuities, particularly with regard to the topics "recognition of documents" and "initiation or continuation of administrative processes" - i.e. the interaction of analogue and digital processes represents an increasing challenge for the effective operation, so that a strategic and systematic expansion of digitization would relieve all those involved in the process (foundation, universities, applicants). Due to that digitization needs and the pressing German Online Access Act (OZG), since 2017/18, the Foundation for University Admissions (SfH) took steps to digitize its admission procedures.

\subsection{1: Cross border Admissions with Dutch DUO using EMREX}

Almost 500 Dutch students start a study in Germany yearly, but more than 20.000 German students go to the Netherlands. That makes them the largest population of foreign students with almost 25\%. At EUNIS 2017 a shout-out was done to German HEI's and organisation in the educational sector to make a step forward and start digitalize the processes for (international) student the enrolment process as example (Strack et.al., EUNIS, 2017). It ended with an invitation to German HEI, educational organisations and Government to pick the glove and start digitalizing. It goes 
without saying that DUO offered their help and expertise to get this done. Since October 2018, the $\mathrm{SfH}$ application portal has enabled Dutch applicants to download transcripts for study programs with nationwide admission restrictions. The EMREX system is used in combination with the DUO diploma database.

\subsection{2: Prototyping Admissions with German Digital Diplomas}

Digitization of different HEI processes based on eID/geID user accounts (eID UAC) combined with (eIDAS) qualified signatures and trust services were done at Hochschule Harz at the projects eCampus (EFRE), TREATS (EU CEF) and StudIES+ (EU CEF) (Strack, Bacharach et.al., EUNIS, 2019, OID, 2019) including the qualified signed notarization of diploma certificates (PDF/ELMO formats) by a so called eNotar role and establishing EMREX connections. Further (ongoing) developments are done at the projects SHIELD ${ }^{1}$ and CyberSecurity Saxony-Anhalt ${ }^{2}$. At the project StudIES + the geID user accounts were extended to eIDAS eID based user accounts and eIDAS remote qualified signatures, successfully tested cross border EU MS. The security level attributes are "qualified" at signature/seal based eIDAS trust services and "high" at eIDAS eID based user authentications. Also, based on this eID user authentication at eID based user accounts, the correct ownership of a diploma certificate can be proven at assurance level "high".

EMREX testings were successfully done together with SfH and UNIT Norway, as well. Besides, connections and testings to the federal OZG user accounts (OZG Nutzerkonto Bund ${ }^{3}$ ) are ongoing.

The $\mathrm{SfH}$ is involved in German and international initiatives aimed at digitizing and digitally validating graduate or diploma certificates. Additionally to the cooperations with the StudIES+ project at HS Harz, first prototypes were developed each jointly with the Bundesdruckerei (BDR) and the SfH based on EMREX/ELMO and blockchain, to prepare nationwide roll-outs. On this basis, the next step towards digital certificates/credentials in Germany was taken. In cooperation with the ministries of the state of North Rhine-Westphalia (NRW), various German universities and the SfH, BDR succeeded in developing a first fully functional prototype for digitally authenticated and machine-readable certificates.

The concept of this prototype is based on the whitepaper of the German Network for Digital Credentials ${ }^{4}$. The prototype uses the university entrance qualifications of German schools in PDF format as an example. By means of signatures in the PDF file and simultaneously with a hash code in a private blockchain database, the university entrance qualifications are digitally authenticated and forgery-proof. To make the certificates machine-readable, the data relevant to the content of the certificate is embedded in the PDF file as an XML file in ELMO format. In addition, corresponding entries in the blockchain ensure that the issuer of the certificate was authorised by a state authority to issue this certificate at that time.

In this form, the certificates generated by this prototype have already been successfully transmitted several times via the European document transport system EMREX to educational institutions e.g. in Sweden and Norway.

For the future, this solution is not only to be used by the one federal state of North RhineWestphalia in Germany. Currently, this solution is also being discussed in other federal states within the framework of the Online Access Act $(\mathrm{OZG})$. Another step would be to further expand cooperation with other projects in the education sector, e.g. the PIM project (see description of PIM project below).

1 https://shield24.de

2 https://cslsa.de

3 https://www.onlinezugangsgesetz.de/Webs/OZG/DE/umsetzung/ozg-infrastruktur/nutzerkonten/nutzerkonten.html

4 http://netzwerkdigitalenachweise.de/whitepaper 


\subsection{Decentralized Admissions}

The admission system modules for the former "centralized cases" including diploma certificates are going to be integrated also for decentralized admissions systems at University Level, like in student information system's (SIS) e.g. HISinOne, CAMPUSonline SIS, HS Harz eID accounts (CAMPUSonline, 2021; HISinOne website, 2021; Strack H. et al.,2019; Strack H., Bacharach et al., 2019; Strack H. et al., 2017). There are different options concerning the level of assurance of authentication (LoA) at the web portal systems: using eID at the portal site or by OZG accounts would meet the LoA level "high" with legally binding for the uploaded documents to the users eID, otherwise UID/PW would mean LoA "low". At eID based cases also a legally binding cross-check is possible between users eID and the certificate owner Identity. The enrollment of new students is also decentralized at the universities.

A document upload can be configured via the SIS admission and enrolment procedure, e.g. HISinOne, CAMPUSonline (CAMPUSonline, 2021; HISinOne website, 2021). Documents to be uploaded are, for example, evidences or certificates. These documents must be checked for authenticity. The contents are partly transferred to the SIS. In artistic degree programmes, letters of motivation or videos are also often required.

The usual format for self-scanned documents is PDF. This saves the submission of paper, but the PDF documents are checked, just like paper documents, by advisors or accountants. The following problems are present in this process:

- No automatic processing of the data, manual data entry and verification

- No protection against counterfeiting, no determination of authenticity / ownership

- Simple summary / compilation of all necessary data.

The new XHEIE standard (GitHub XHochschule, 2021) is intended to enable the automatic processing of data. In near future, a data model (XML) is to be provided as a supplement or maybe as an alternative to a verification. Within the framework of XSchule, an automatically processable XML document will also be available for school reports (see also 1.1.2). XHEIE focuses on evidence from higher education institutions. This XML data is required, for example, for applications for Master Programmes, job applications or BAföG (student funding).

A new challenge with digital documents is the lifespan of the document. The specification of the data model must be long-term stable and downward compatible. It must be guaranteed that an electronic document from today can still be processed electronically 5, 10 or 20 years from now. This challenge must be solved during the import. When exporting, the most up-to-date specification possible should always be used. XHEIE version 0.4 imports dozens of external XSD specifications. Java classes can be created from the XSD (e.g. with JAXB) ${ }^{5}$. There are more than 350 files in over 60 folders. At this scale, stability becomes a problem.

However, the XHEIE project does not address many technical challenges (XHochschule Website, 2021). Therefore, the standard does not eliminate all the problems listed above. It is not defined how the XML files are to be transferred from one place to another. Currently, the XML files are probably given directly to the users, e.g. as a download or email (alternatively OZG UAC or EMREX). Without a technical specification, it will be difficult to achieve a compatible implementation by all developers in all sectors. Instead of setting a central target, these deficits will have to be addressed in many (small) projects. There is a risk of a heterogeneous software landscape for digital evidences in Germany.

It is not specified how the file is to be assigned to an identity. XHEIE allows a variety of identifiers, but does not define which one must be used. Thus, a variety of different procedures may have to be supported by the SIS. The new RegMoG (Register Modernisation Act) provides a remedy here. However, implementation is not expected before 2024 (RegMoG, 2021).

5 http://xhochschule.de/def/xhochschule/0.4/xsd/xhochschule-nachweis.xsd 
Benefits for students and institutions would be even greater, if the XHEIE project would extend its mission from defining digital standard formats for the current paper processes towards optimizing also university processes themselves. However, this is currently not the main scope of the project.

\subsection{Personal document management}

For many people, handling and managing digital documents is a new challenge of digitization. Many files in different formats and messages have to be stored, organized and found again. The stack of paper is also digitized. Various solutions to this challenge are currently being discussed.

At the beginning of the XHEIE project, personal document management was also included. Today it is not in the scope. Therefore, a technical standard is defined here as well. In some projects, e.g. PIM, the use of wallets is therefore being considered. There are some (commercial) app's that can be used. An attempt to relax this challenge by using verifiable credential containers or OZG accounts leaves potential for improvements regarding user friendliness.

A university must decide on an app and thus determines what the student can use. The app must be individually connected to the SIS. There is no guarantee that data can be exchanged between two different apps. Another university with a different SIS may have chosen a different app. This circumstance can make student mobility more difficult. If students were to be given the choice of app, a large number of connections would have to be programmed in the SIS which would mean a large cost factor. One possible solution would be to create an open API or another solution would be to provide a public infrastructure. Both could also be combined.

\section{Use Cases for HEI/EDU - Credentials/Certificates (UC2) as a Paper Supplement}

Establishing digital credentials/certificates as "final" step of the student journey successfully depends on the one hand on solving regulatory and technical challenges, on the other hand, on creating added value for users to foster broad acceptance.

As an intermediate step, a combined digital and paper-based version of credentials was set productive at the University of Göttingen in 2017. During the first three years more than $\underline{15.000}$ certificates have been issued successfully.

The approach solves the following dilemma: issuing credentials digitally only is technically and legally challenging or even practically impossible. However, for most use cases a digital copy of such a credential is widely accepted.

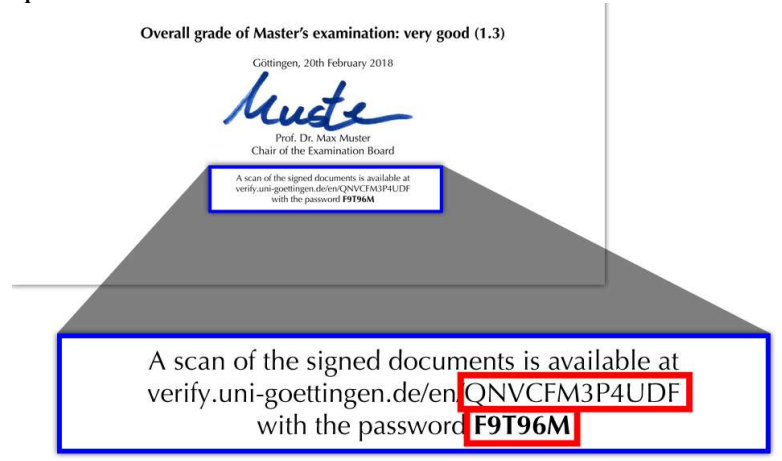

Figure 1: digital copy with verification link 
The basic idea is to add some additional value to this digital copy, that makes it even more preferable compared to the (legally binding) paper version. In our case we added a verification link, consisting of $12+6$ alpha numeric characters. Clicking on this link would download a reference copy of the digital certificate from the university's archive system.

While paper documents could be forged rather easily, forging the digital copy now would involve breaking into the university's server. So it combines the native advantages of digital documents such as easy handling, lossless duplication and fast transfer with increased fraud resistance, leading to a high acceptance rate with graduates as well as i.e. future employees.

The most important missing feature is machine readability. From a technical point of view it would by rather easy to add some kind structured data (i.e. ELMO-XML) as part of the digital copy. However, a widely accepted and stable standard is still needed, since including data in the "wrong" data format would decrease the acceptance of such digital certificates. Another feature missing is some kind of digital signature or certification, ideally long term (10+ years) valid by itself.

Applying modules from use case 1 for university credentials only StudIES+ (StudIES+ Website, 2019/20) presents a hybrid solution by eIDAS/EMREX (HS Harz, SfH). Also, Bundesdruckerei and $\mathrm{SfH}$ are developing a minimal viable product of digital credentials. A comprehensive vision of a possible solution has been developed by the Digital Credentials Consortium as a global solution. (Duffy, Pongratz, \& Schmidt, 2020) On the other hand, PIM represents an EU solution. (PIM website, 2021)

The (automatic) generation and delivery of reports / documents in SIS is often part of a more comprehensive process. Specialised systems are used to implement these processes. These are document management systems (DMS). In the German-speaking world, more functions are assigned to these systems than elsewhere. The focus is on the aspect of document management, e.g. within the framework of a workflow for processing and release. In addition, standard functions for storage, archiving and record keeping are in use.

The SIS, like HISinOne, is complemented with these functions and processes. A challenge that has not been considered much yet is to connect the new requirements of digitisation with these already digital processes. The creation of a university certificate involves many university administration offices (examination office, steering committee, external examiners, etc.) and the students themselves. A machine-readable format can also only be created after these processes have been completed and therefore only in conjunction with the DMS.

The electronic document may only be retrieved or passed on after it has been released. An electronic document must show exactly the same contents as the paper document. A technical protocol for electronic data transmission must be consider this. The data model of the protocol could be ELMO with embedded qualified signed PDF. A strongly authenticated binding between certificates owner identity and the account user identity could be done at eID account level with LoA "high" (university eID account e.g. at HS Harz, or by OZG eID account).

\section{Use Case 3: Student Inter*national Mobility}

International or national mobility follows in the student life cycle. The digitalisation challenge arises from the interaction of separate institutions (home and host university), possibly located in different countries or even continents. Not only that media discontinuities are more probable, but also the standardisation and interoperability efforts need to solve national and regional differences.

The objective of the Platform for Inter*national Student Mobility PIM, started as project funded by the Federal Ministry of Education and Research, is to support digital recognition processes for student achievements (PIM - Platform for International Student Mobility, 2021). The PIM contributions to digitalisation encompass several elements: 1.the usage of the European data standard 
ELMO 2. the availability of a central module data base in EDCI standard, 3. their combination in a digital workflow as SaaS, 4. a database with reference cases for recognitions, as online orientation service, 5. strong integration with the Student Information Systems (SIS) of the universities. In the following, the mentioned contributions will be shortly described in their current state of implementation. In a further step, the future perspective will be evaluated.

1. The ELMO data standard of the EMREX network is used for the digital transfer of student Transcript of Records among higher education institutions (HEI). The added value for the user is a nearly instantaneous transfer of both structured data and verified PDF files. However, ELMO provides less data than required by German examiners, forcing users to enter more information manually.

2. A further data standard comes into play on PIM: the Europass standard EDCI. Given the more extended xml structure, module descriptions with comprehensive data can be "translated" into this format and serve as common standard for German HEIs and for the SIS covering the overwhelming majority of the HEI users. EDCI allows for big degrees of freedom, which lead to an intense cooperation among SIS and PIM in order to establish a semantic interoperability. The implementation stage is quite advanced and several HEIs are ready to import their EDCI module data, so that PIM build a centralized database available to all platform users.

3. The two data standards come to a symbiosis in the PIM digital recognition workflow. Students create a recognition request made of two data blocks. One block contains the information on the modules of the external (receiving) institution, whereas the other indicates the modules of the home HEI (sending institution). The ELMO-transfer initiates the workflow and provides the data of the external modules. These are set in an $m$ to $n$ relationship to the internal modules, which are available in EDCI format. In the next step, the internal administrative processing follows, having as outcome a recognition result, which is brought via API into the local SIS. In a HEI landscape described as strongly autonomous, voices warned at PIM birth that a SaaS standardisation for such diverse procedures and diverse stakeholder expectations may turn out to be quite impossible. After 1 year of project duration, an MVP workflow, configurable in length and in the organisational entity level is functional. This should be regarded as outcome of the collaboration among $11 \mathrm{HEI}$, analysing and designing the service after iterative user tests.

4. The PIM data model strictly separates personal and non-personal entities. It allows for recognition cases to be still available for reference even if users have already received their results, and these may even have been deleted. In this way, PIM provides another service to all users: the search for reference cases. This search offers matches along with the recognition processing and supports students and examiners in the creation and decision-making process.

5. PIM as platform lives from the integration with the HEI SIS, expressed in the implementation of several interfaces. One is the above mentioned interface for EDCI module data import. A further interface transmits the recognition results back to the SIS. Since both external module data and internal module data as well as the corresponding grades are needed in the SIS, PIM developers created a double ELMO format that transfers the recognition via API back to the sending institution. Part of the PIM goal was the implementation of the EMREX interfaces for import and for export in SIS, not only with PIM as intermediary, but also for a decentralised usage.

Further instances of the EMREX decentralised implementation are the NCPs created in several HEIs. At the University of Göttingen, the NCP function is active and allows ToR to be exported. The University of Göttingen and HS Harz validated their NCP vs. UNIT Norway for valid transfer of signed ToR/diploma certificates. A similar transfer was done by University of Göttingen and BDR vs. DUO Netherlands. With the project liveSciences ${ }^{3}$, funded by DAAD and the Federal Ministry of Education and Research (liveSciences ${ }^{3}$ : Transnational and Digital Linked Life Sciences, 2021), important steps are made to extend and establish new EMREX contact points outside Europe. An open policy question overall is the minimum level of trust for authentications and signatures (HS Harz operated with Level of Assurance "high" for both (i.e. eIDAS eID \& TS/QeS). 
To summarize, PIM can be seen as real-life lab for digitalising the administrative processes of student mobility, by combining various approaches to data standardisation and integration. In the future, the lessons learned and the available software components can be reused and further developed for the integration into larger platform eco-systems (such as the evolving national meta-platform for education) as well as for connecting with European initiatives such as Erasmus Without Papers (EWP).

\section{Additional Use Cases, Architecture Aspects, Discussions}

An example for a use case, which involves also (company) partners outside from university domains, is the eInternship use case. It involves besides the student and the student office, a professor, an eInternship Delegate of the faculty and an (external) eInternship Employer (PEY), which have to sign some forms together/mutually before students starting at PEY. The eNotar use case is a kind of meta use case, i.e. trustworthy signed eNotar statements are important for secured and trustworthy digitalisation of many multi party processes, e.g. for applications of graded pupils (A-level graduation certificate notarization) at universities/enrolments. While other MS have electronic Diploma Registers (including the A-Level) like The Netherlands or Norway (by law enabled by DUO resp. UNIT) this is not the case in Germany, where we have a "diploma paper" driven pupil/student live cycle at schools and universities/HEI, which are organized federally according to local government laws. In Germany, the Bundesverwaltungsverfahrensgesetz $\$ 33 \mathrm{VwVfG}$ (and references at local government laws), would allow the electronically signed eNotarization of public administration office documents. We propose digitalisation use case models, which would allow the schools / HEI on request of a student/pupil/ applicant to upload the eDiploma doc + Notarization Text Statement by GeID to eNotar accounts at federally distributed offices at SfH or HEI or other administration offices - with legally binding. The eNotar offices would sign these docs by QES, and store or forward this eDiploma to the requested target office. Therefore, the schools would need only a simple electronic infrastructure (no eSignature one): office software, eID/PA \& eID client, card reader and internet access. Of course, also an integration of eIDAS remote eSignature infrastructure at school level would be feasible (with higher integration costs), if wanted. The eNotar/register proposal wase combined with the EMREX architecture (using the ELMO xml) to be integrated there as a result service, by which the student could trustworthy download and transfer his eDiploma to other HEI and employers for application (tested with UNIT Norway). Another kind of use cases was established for secure digitisation by combing eNotar and MyCredentials features, to generate derived (soft) user identities deID, based on eIDAS eID (remote) authentication of users (LoA "high"), typically for use in local HEI domains. To enlarge the trustworthiness areas of deIDs (in time or space/domains), these could be signed by eNotar. Also eNotarization of matching of different deIDs for the same person are possible, resulting in another kind of SSI. 


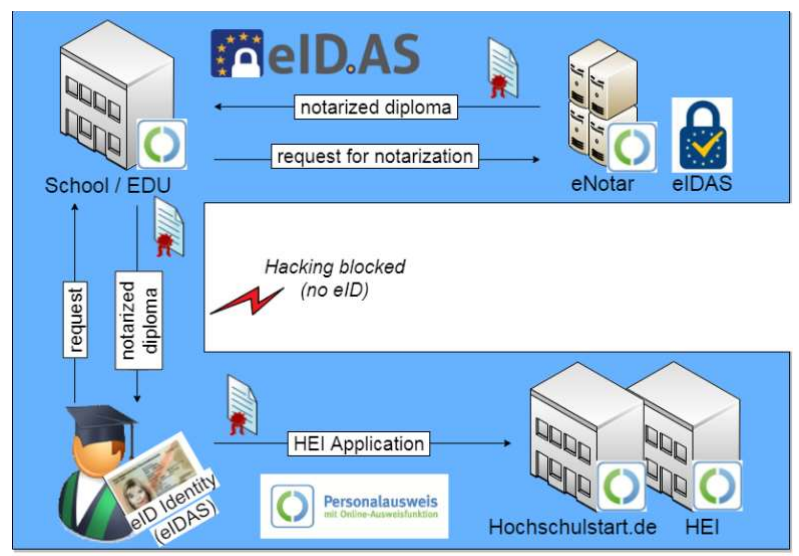

Figure 2: eIDAS protected eNotar workflow (HS Harz)

Another concern are requirements for self sovereign control of credential/certificates proliferation and privacy protection SSPRO2 (as severe additional risks to id proliferation). The eNotar notarization approach combined with a LoA "high" authenticated transfer of credentials/certificates (OZG, eID eIDAS) would help, also their notarization would be individually protect against illegal proliferation and validation attacks (FinD), also by additional integration of watermarks (Strack et.al., 2017) or of crypted deIDS (instead of eID), where the decryption (keys) are under control of the credentials/certificates owner or an trusted party (via Your/MyCredential). Another alternative way to digitise graduation or exam certificate processes is done by the community "Digitale Nachweise", where private blockchain storages are done for crypto hashes/ signatures of such certificates, e.g. for use by certificate checks of stakeholders by smartphone services.

Comparing these certificate scenarios to the eIDAS based eNotar scenarios, we have to state, that the eNotar one has an overall LoA "high" security and authentication/privacy level with fully legally binding. This is not the case, at the alternative way. Also a LoA "high" binding of the certificate owner ID attributes to the eID of the owner or his eIDAS account is not integrated. Another questions to clarify are different security questions of the blockchain certificates approach, concerning e.g. crypto agility aspects, open standardization, added trust values by private blockchains or open questions concerning long term preservation (BSI, 2019/2020).

\section{Future Developments \& Standards, Challenges}

Further upcoming developments like the integration of the EDCI and VC standards or of the Single Digital Gateway (SDG, EU) or the standardization of certificate formats XHEIE will bring some challenges for the next steps of HEI/EDU digitization. Compared to EMREX/ELMO an additional secure transportation infrastructure is needed for EDCI.

\subsection{Digital Diplomas - from PDF to Verifiable Credentials}

Internationally, work is now also being done to no longer see credentials as documents, but as individual, verifiable credentials ("Verifiable Credentials"). These verifiable credentials (VC) can be certificate grades, permission to drive various motor vehicles, permission to hold a doctoral degree, a welding certificate and many others. They can also be confirmation of an identity or authorisation to use a software system. These approaches are mostly based on the $\mathrm{W} 3 \mathrm{C}$ data standard (from which the EDCI data structure of Europass has also evolved). 
With the solution embedded in the PDF format, the unique identification of the certificate holder could only be created via a secondary system. This could be done, for example, by integrating the German OZG user account into the SfH's DoSV technical procedure to enable the identification of applicants with a higher level of trust and the verification of authorizations. To date, only a passthrough of the entire PDF with all data to consumers has been possible. The VC approach covers the last two outstanding requirements for this digital solution: implicit, unique identification of the digital badge holder, and allows data to be shared dedicatedly from the VC holder to third parties.

In the European project EBSI $^{6}$ (European Blockchain Infrastructure), an infrastructure was set up in parallel to also process (in the use case "Diploma") digital certificates on a VC basis. They are currently working on expanding the digital proof solution developed by BDR into a verifiable credential-based solution using this infrastructure.

\subsection{German and European Developments \& Standardization, Summary}

National initiatives and policies have the goal to align with these European standardization efforts. XHigherEducationInstitutionExchange (XHEIE) and other national standardization efforts directly reference e.g. to EDCI and ELMO.

Additionally, with the Act to Improve Online Access to Administrative Services (OZG), which came into force on August 18, 2018, the federal and state governments want to create a joint interoperable portal network for digital administrative services, with 3 LoA levels for user authentication: low, substantial, high (eID).

The portal network is intended to ensure that users have barrier-free access to electronic administrative services of these administrative bodies via all administrative portals of the federal and state governments. The implementation deadline is December 31, 2022. Under public law, German universities and the $\mathrm{SfH}$ are covered by the scope of the OZG.

By the EU Student eCard Initiative, funded by EU CEF, several projects were developed/ing, e.g. MyAcademicID, ESMO, SEAL to support cross border student mobility, using eIDAS and blockchain primitives (with EMREX/EWP, Mincer-Daszkiewicz J. (2017). The EDSSI project is going to build an infrastructure for using Student eCard authentication, based on that.

In 2018, the European Parliament and the European Council decided to create a single digital gateway (cross border) to the administration in the EU with the Single Digital Gateway (SDG). The SDG and OZG have the same goal: The digital offering of the administration should be citizenoriented and user-friendly. In addition, all services should be available via a single portal.

According to the SDG, the citizen portals of all member states are to be bundled in the overarching EU portal by the end of 2020. Users will then be able to search specifically in all EU languages and access all national portals directly. By the end of 2023, selected EU services should even be "fully" usable online, i.e. EU-wide without paper applications or searching for authorities. The goal is to realize the once-only principle, so that citizens and companies only have to provide certain standard information to authorities and administrations once. According to EU Regulation 2018/1724, one of the 21 selected EU services is also "submission of an initial application for admission to a public higher education institution." This means that German universities and the Foundation for University Admission are affected by the SDG. Based on the DCC whitepaper, the project Digital Credentials for Higher Education Institutions (DiBiHo) explores interoperability between the existing standards on an international level (DiBiHo, 2021).

In conclusion, the multiple initiatives aiming at increasing the digitisation level in HEIs make progresses, also due to the legal European and German regulations, also including the common use of eGovernment Standards at HEI/EDU.

6 https://ec.europa.eu/cefdigital/wiki/display/CEFDIGITAL/EBSI 


\section{References}

Author Biographies (2021), https://www.eunis.org/eunis2021/wp-content/uploads/sites/18/2021/05/ EUNIS_2021_paper_15.pdf

HISinOne website (2021). HISinOne. Retrieved February 26, 2021, from: https://www.his.de/hisinone

GKV website (2021). GKV Datenaustausch. Retrieved February 26, 2021, from: https://www.gkvdatenaustausch.de/studenten_meldeverfahren/studenten_meldeverfahren.jsp

Digital Credentials website (2017). Digital Credentials at University of Goettingen. Retrieved February 26, 2021, from: https://verify.uni-goettingen.de/en

DiBiHo website (2021). Digital Credentials for Higher Education Institutions (DiBiHo).Retrieved February 26, 2021, from: https://www.dibiho.de

Duffy, K. H., Pongratz, H., Schmidt. (2020). Building the digital credential infrastructure for the future. Retrieved February 26, 2021, from: https://digitalcredentials.mit.edu/wp-content/uploads/2020/02/white-paper-building-digitalcredential-infrastructure-future.pdf.

PIM website (2021). PIM - Platform for International Student Mobility. Retrieved February 16, 2021, from: https://pim-plattform.de

Mincer-Daszkiewicz J. (2017). EMREX and EWP offering complementary digital services in the higher education area. EUNIS Conf. Proc., Uni. Münster, 2017

Strack H., Karich C. (2007). A Distributed Architecture for the Management of Data Flows within the Bologna Process using E-Government Standards. EUNIS Conf. Proc., Grenoble, 2007

Strack H., Bacharach G., Klinner S., Otto O., Schmidt A. (2019). eIDAS eID \& eSignature for HEI/EDU Applications. In: European Journal of Higher Education IT 2019-1. https://eunis.org

Strack H., Klinner S., Otto O., Schmidt A. (2019). eIDAS eID \& eSignature based Service Accounts at University environments for cross boarder/domain access. In: Roßnagel $\mathrm{H}$., Wagner S. and Hühnlein D. (Hg.): Proc. of the Open Identity Summit 2019. LNI (GI) P293 Bonn, S. 171-176. https://dl.gi.de/handle/20.500.12116/20986.

Strack H., Wefel S., Molitor P., Räckers, M., Becker J., Dittmann, J., Altschaffel, Marx Gómez J., Brehm N., Dieckmann A. (2017). eID \& eIDAS at University Management - Chances and Changes for Security \& legally Binding in cross boarder Digitalization. In: EUNIS Conf. Proc. 2017, S. 133-141.

StudIES+ Website (2019/20). Student's Identification and Electronic Signature Services. Retrieved February 26, 2021, from: https://www.studies-plus.eu

CAMPUSonline (2021). CAMPUSonline. R. Feb. 26, 2021, from: https://www.campusonline.tugraz.at/home/

liveSciences ${ }^{3}$ website (2021). liveSciences ${ }^{3}$ : Transnational and Digital Linked Life Sciences.

Retrieved May 12, 2021,https://www.uni-goettingen.de/livesciences3

Otten J., Venema S., Roet M., Drummen N. (2017): Digital Diploma Data (In Deutschland?). EUNIS Conf. Proc., 2017, Retrieved from: https://www.eunis.org/eunis2017/wp-content/uploads/sites/10/2017/06/

EUNIS_2017_paper_24_new.pdf

GitHub XHochschule (2021). Retrieved May 17, 2021, from: https://github.com/OZG-TFBildung /XHochschule

XHochschule Website (2021). Retrieved May 12, 2021, from: http://www.xhochschule.de/event/ xhochschule/2021-03-24/videos/XHochschule15_00_Gesamtaufnahme.mp4 - Minute 24 to 28 
Progress on Digitization of Higher Education Processes towards Standards EU \& DE Strack et.al.

Registermodernisierungsgesetz - RegMoG (2021). Retrieved May 17, 2021, from: http://www.gesetze-im-internet.de/regmog/BJNR059100021.html

BSI (2019). Blockchain sicher gestalten - Konzepte, Anforderungen, Bewertungen. Retrieved May 21, 2021, from https://www.bsi.bund.de/SharedDocs/Downloads/DE/BSI/Krypto/Blockchain_Analyse.html

BSI (2020). Sicherheitsuntersuchung ausgewählter Blockchain-Anwendungen https://www.bsi.bund .de/SharedDocs/Downloads/DE/BSI/Krypto/Blockchain_Studie-374.html

EU Student eCard Website (EU), (2021), EU Student Card. Retrieved May 21, 2021, from https:/ec.europa.eu/cefdigital/wiki/display/CEFDIGITAL/EU+Student+eCard

MyAcademicID Website (2021). Retrieved May 21, 2021, from https://myacademic-id.eu/

SEAL Website (2021). Retrieved May 21, 2021, from https://project-seal.eu/

ESMO WebSite (2021). Retrieved May 21, 2021, from https://www.esmo-project.eu/

EUF Website (2021). EDSSI. Retrieved May 21, 2021, from https://uni-foundation.eu/project/edssi/ 